\title{
A AÇÃO EMPREENDEDORA DE PRODUTORES DE JOGOS INDEPENDENTES INSPIRADA NO EFFECTUATION
}

Jardiel De Moura Gomes ${ }^{1}$

Fernando Paiva Júnior ${ }^{2}$

Jose Lindenberg Julião Xavier Filho ${ }^{3}$

\footnotetext{
${ }^{1}$ Centro de Ciências Sociais Aplicadas - CCSA / Programa de Pós-Graduação em Administração - UFPE / PROPAD / Universidade Federal de Pernambuco - UFPE

${ }^{2}$ Universidade Federal de Pernambuco - UFPE

${ }^{3}$ Núcleo de Gestão (NG) / Centro Acadêmico do Agreste (CAA) / Universidade Federal de Pernambuco - UFPE
} 


\title{
A AÇÃO EMPREENDEDORA DE PRODUTORES DE JOGOS INDEPENDENTES INSPIRADA NO EFFECTUATION
}

\begin{abstract}
RESUMO
Este estudo teve como objetivo desvelar a ação empreendedora dos produtores de jogos independentes. Foram estudados quatro estúdios de jogos independentes nas cidades de São Paulo (SP), Curitiba (PA), Recife (PE) e João Pessoal (PB). Na composição do referencial teórico, foram escolhidas duas abordagens teóricas, a ação empreendedora desenvolvida por Paiva Junior (2004) e o effectuation como teoria complementar, proposta por Sarasvathy (2001). Foi desenvolvida uma pesquisa qualitativa que contou com quatro entrevistas semiestruturadas, analisadas por meio da técnica análise de conteúdo temática. Os resultados revelam a ação empreendedora dos produtores independentes, conhecidos como desenvolvedores indie, destacando aspectos como a articulação em redes organizacionais como forma de ação social que tem por base a parceria e valores compartilháveis até pelo fato de que a lógica effectual inspira a ação empreendedora dos desenvolvedores de jogos indie.
\end{abstract}

Palavras - chave: Produtor Independente. Ação Empreendedora. Effectuation. Produção de jogos Indie.

\section{INTRODUÇÃO}

A velocidade pela qual as mudanças acontecem na era tecnológica estimula a discussão com respeito ao modo como ocorre à ação empreendedora, visto ser o empreendedor que atua junto a plataformas digitais o sujeito promotor de mudanças sociais na era das novas tecnologias. Neste bojo, as mudanças ocorrem não apenas na dimensão dos produtos, mas também nas ideias e nos modos de vida das pessoas (NAMBISAN,2017; VON BRIEL; DAVIDSSON; RECKER, 2018). Diante de tal evidência estudar como os sujeitos interferem ou emprestam significados as ideias que circulam nos produtos (literatura, filme, pinturas) ganhos revela em termos de pesquisa social.

$\mathrm{Na}$ medida em que o empreendedorismo é visto como fenômeno social interativo e instiga as inquietações relativas ao modo de lidar com práticas sociais que vão de encontro aos limites impostos pelo formalismo, cuja base se projeta na ocorrência de uma ruptura com movimentos seguros e estáveis (SOUZA; PAIVA JÚNIOR, 2012). Nesse contexto, o empreendedor ganha destaque na condição de objeto de análise e éthos da ação social. A ruptura com os movimentos seguros e estáveis que ou autores discutem o que ocorre no cotidiano social (WILLIS, 1997).

O videogame vem se tornando uma das principais mídias culturais da sociedade contemporânea (SHAW, 2010; CHEN, 2013), ao aguçar o imaginário coletivo dos jogadores (LATORRE, 2015) e fazer circular ideias e modos de vida nos textos (jogos) (SANSON, 2009). Portanto, o ato de estudar o sujeito que desenvolve de tal ação no universo digital e o modo como ocorre tal ação representam o esforço de estudar ação humana como extrato da sociedade contemporânea. Logo, a finalidade deste estudo reside em compreender como

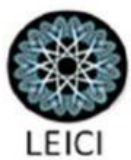


ocorre a ação empreendedora emergente do comportamento de produtores de jogos independentes com inspiração no olhar effectual.

Ao se rediscutir o empreendedorismo como fenômeno social e interativo é possível entender que o ator que desenvolve novos negócios é um agente transformador, dialógico e reflexivo, operando sob a inspiração de suas experiências (DENTONI, 2017). Essas experiências são vivenciadas e desenvolvidas também por meios digitais, que vêm se popularizando e tendo seus custos reduzidos a partir de novas plataformas digitais, sendo esse o ambiente o espaço onde se centra a prática empreendedora no campo dos games indie (PEREIRA, 2016).Tal prática promove liberdade de ação em cenários de instabilidade e incerteza, autenticidade na configuração da arquitetura do jogo e aperfeiçoamento na criação visual e artística (NAMBISAN, 2017).

$\mathrm{O}$ produtor de games indie atua de forma independente na escolha das ferramentas, linguagens, frameworks, plataformas, programação, desenvolvimento da arte, animação, dublagem e captura de movimentos, além de manter o relacionamento com fabricantes de hardware e softwares, a fim de garantir a compatibilidade desses componentes e explorar o potencial de atividades relacionadas ao game (GEDIGAMES, 2014).

O perfil dos desenvolvedores independentes é diversificado, tem equipes reduzidas e recursos escassos a considerar que a maioria deles não é apoiada pela figura do publisher, agente que publica jogos eletrônicos de produção própria ou aqueles confeccionados por uma empresa desenvolvedora de jogos eletrônicos, responsável por financiar o desenvolvimento e comercialização do game (JOHNS, 2006; GEDIGAMES, 2014). De todo modo, o relacionamento entre o desenvolvedor e o publisher é problemático por este exigir do desenvolvedor esforços intensos para dar um formato mercadológico ao produto (XAVIER FILHO, 2017).

O desenvolvedor indie atua por meio de plataformas digitais e busca aporte financeiro para investir na sua produção, para isso, ele acessa formas diversificadas de financiamento, a exemplo de recursos próprios, subsídios de familiares, crédito pessoal, suporte de investidores anjo e crowdfunding (NEGRÃO; TOALDO, 2013; XAVIER FILHO, 2017).

O game como produto possui uma complexa estrutura de produção, que envolvem diversos atores e uma ramificada estrutura processual e de subcontratações (PERUCIA; BALESTRIN; VERSCHOORE, 2011; NEGRÃO; TOALDO, 2013). Essa condição de produção sugere certa performatividade do empreendedor na feitura do game, em especial o desenvolvedor indie que não conta - via de regra - com os recursos e expertise das grandes publicadoras. A questão que se projeta é que o desenvolvedor indie explora seu espaço no mercado, mesmo diante de uma estrutura comercial e produtiva inóspita para sua ação, convivendo com incertezas e ambiguidades presentes no universo empresarial e lidar com as ameaças tendo que transformá-las em oportunidades.

Diante de tal ambiência, e considerando a performatividade necessária ao empreendedor para viabilizar suas produções, este estudo se presta a desvelar a ação empreendedora dos produtores de jogos independentes. Para compor o quadro teórico a partir do qual se vê essa dinâmica e serão discutidas a ação empreendedora e a abordagem effectual.

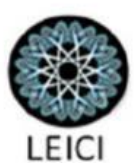




\section{REFERENCIAL TEÓRICO}

O referencial teórico deste estudo está organizado de maneira a fundamentar e alcançar se objetivo: compreender a ação empreendedora emergente do comportamento dos produtores de jogos independentes: um olhar effectual. Para o alcance desse objetivo, o referencial teórico está dividido em dois momentos, sendo o primeiro a ação empreendedora indie e o segundo o effectuation.

\subsection{A ação empreendedora no contexto do desenvolvedor de jogos Indie}

O empreendedor realiza atividades de trocas com outras organizações que são ancoradas em crenças, rotinas e hábitos. Já a ação empreendedora pode ser definida como extrato da realização de tarefas desenvolvidas por empreendedores no sentido de enfrentar riscos e incerteza na criação de uma organização criativa e inovadora (SPEDALE; WATSON, 2014).

A ação empreendedora é composta por características do empreendedor, como proatividade, desenvolvimento pessoal e capacidade de gerenciamento, mas seu foco está centrado no seu relacionamento com outros agentes para o alcance de resultados. Para alcançar seus objetivos, o empreendedor combina recursos para desenvolver e comercializar novos produtos e aprimorar seus negócios. Ao identificar e explorar as oportunidades esse ator integra suas atividades de maneira inovadora, gerando aprendizagem (THEODORAKOPOULOS et al., 2014).

As características da ação empreendedora se projetam em três categorias estruturantes para Paiva Júnior (2004), sendo eles o estilo criativo, a expertise e a interação social. O estilo criativo está presente na consciência do empreendedor, o qual se revela como ser capaz de intervir de maneira reflexiva no seu ambiente de negócios, uma vez que possui um conjunto de competências que o posicionam com alto desempenho frente a seus interagentes (PAIVA JÚNIOR, 2004; DENTONI, 2017). Dessa categoria, emergem dimensões como identidade, autonomia, convivência com o risco, disposição pessoal e resiliência. Essa dimensão é a mais recorrente pelos desenvolvedores indie, pois é marcada pela busca da autonomia, disposição pessoal e convivência com o risco em uma produção autoral, genuína e criativa.

A expertise permite ao empreendedor se tornar capaz de reconhecer oportunidades sob o fundamento da sua experiência acumulada (SALUSSE; ANDREASSI, 2016). Nessa dimensão, ele adquire conhecimento especializado, inclusive para reconhecer oportunidades de negócios com base nessa experiência e na habilidade de colocar em prática o que foi aprendido. Nessa categoria as dimensões são: desenvolvimento de competências, alteridade, mediação e inovação.

A interação social se fundamenta na relação de reciprocidade que pressupõe a comunicação do empreendedor com os parceiros chave de sua rede social. Essa dimensão abarca a capacidade relacional desse empreendedor, que constrói relações de confiança, disponibilidade, fidelidade, cooperação e adaptação contingencial. Os componentes dessa dimensão são: ação política e social, oportunidade, parceria, ação de adaptação contingencial, cooperação técnica e internacionalização. Por meio da interação social, a produção de jogos independentes (indie) é potencializada e a ausência do publisher guiador do processo de

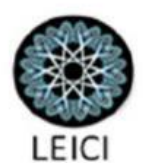


produção tende a ser superada.Os games são produzidos, portanto, por meio de parcerias, colaboração e trabalho em rede, movimento que diminui o preço de produção e dispensa a presença física dos colaboradores da equipe, desonerando a produção numa vivência integradora de saberes.

\subsection{Effectuation inspirando a ação empreendedora dos desenvolvedores de jogos indie}

Diante do desafio de compreender como ocorrem as mudanças nas organizações ao longo do tempo e seu impacto na gestão e institucionalização das práticas gerenciais, tais como plano estratégico, plano de negócio e qualificação de cenários, surge o effectuation como novo modelo de gerenciamento em contestação ao modelo tradicional de causa e efeito (MEYER; ROWAN, 1977). A racionalidade effectual não é um desvio da racionalidade clássica causal, e, sim, um modo alternativo de racionalidade, baseado em uma lógica distinta da lógica causal (SARASVATHY, 2001).

Sarasvathy (2001) debate a lógica do effectuation como uma forma de tomada de decisão pautada em escolhas em meio a efeitos que podem ser produzidos a partir de um conjunto de possibilidades, eliminando a premissa de objetivos pré-existentes. Por meio de suas ações, o empreendedor gera resultados a partir da combinação de recursos, à medida que reduz as incertezas que cercam seu empreendimento possibilitando sua adaptação a contingências (LEUCZ; ANDREASSI, 2015).

Em conformidade com a lógica effectual a incerteza passa a ser encarada como um recurso e um processo sobre os quais ocorre a tomada de decisão. Na mesma direção, a ambiguidade inicial de objetivos é encarada como um fator de criatividade gerador de oportunidades à medida que o empreendedor está mais aberto a aproveitar as contingências que surgem no percurso da criação de seu empreendimento (SARASVATHY et al., 2005; TASIC, 2007).

O modelo effectual é recomendado para empreendimentos intensivos em tecnologia voltados para criação e captura de valor dos empreendimentos. No entanto, eles experimentam dificuldades na definição de um negócio devido a níveis elevados de tecnologia em meio às incertezas do mercado (BERENDS et al., 2014; REYMEN, 2016). Portanto, o desenvolvimento de um modelo de negócio para o empreendedor de jogos indie conta com sua experimentação, aprendizagem e flexibilização (BOCK et al., 2012; REYMEN, 2016).

Sarasvathy (2003) assevera que existem padrões diferentes utilizados por empreendedores que rompem com o modelo estruturado, caracterizado por causa e efeito. Ao arquitetar a teoria effectuation a autora propôs uma perspectiva filosófica na qual o ser humano transforma a realidade em novas possibilidades, que significa que o "processo empreendedor segue um percurso criativo e, não somente de descoberta e alocação de recursos" (RONDANI, 2012, p.3).

O modelo clássico de gestão indica que existem meios estruturados para se alcançar o objetivo desejável (causal), já a perspectiva effectual envolve a elaboração diversificada de objetivos, compreendendo que as limitações e dificuldades habitam um ambiente dinâmico e interativo. Wiltbank et al. (2006) comenta que, após acessar os "meios", o empreendedor avalia as direções possíveis e busca pessoas com o intuito de alcançar esse objetivo. No

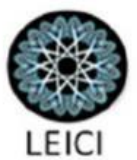


mercado de jogos independentes o desenvolvedor, ao constituir uma ideia, monta uma equipe para produção do game, como algo aberto à mudança durante todo o processo de confecção do jogo. Portanto, a teoria do Effectuation sugere que o tomador de decisão não fique ancorado à previsibilidade do cenário, mas atue como agente transformador que provê as condições necessárias para garantir um contexto favorável (PORTO, 2015).

Wiltbank et al. (2006) classifica o processo de effectuation em três categorias: identidade, conhecimentos e redes sociais. No que tange à identidade os empreendedores refletem a respeito de quem são eles, pelo que eles conhecem e quem eles conhecem, de forma a imaginar o que possam vir a realizar. Isto projeta a ênfase em eventos futuros que eles podem controlar ao invés de prever (SARASVATHY, 2008). Já no conhecimento os empreendedores começam a divulgar seu projeto para outras pessoas, de modo a obter inputs sobre como proceder com algumas das coisas que eles poderiam fazer (WILTBANK et al., 2006). Por fim, na rede social, à medida que os empreendedores encontram pessoas ávidas por participarem da construção de algo aberto a mudanças eles vão buscando obter comprometimentos reais destes stakeholders potenciais (SARASVATHY, 2008).

Em análise da ação empreendedora de Paiva Júnior (2004) e do Effectuation de Sarasvathy (2001) se buscou alinhar as duas teorias para uma investigação detalhada da ação empreendedora dos produtores de jogos indie. Assim, em análise associativa pode-se compreender suas interações, conforme figura 1.

Figura 1: Ação Empreendedora e Effectuation

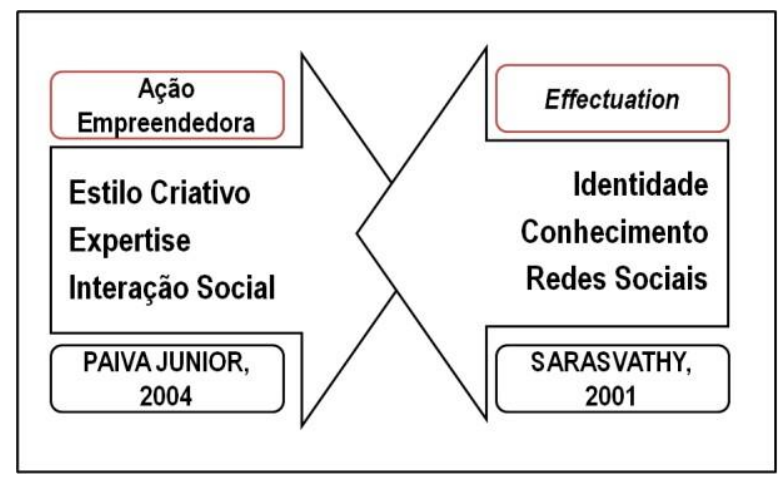

Fonte: Elaborado pelo Autor (2017)

Quando identificadas as categorias estruturantes da ação empreendedora (estilo criativo, expertise e interação social) é possível a associá-las às categorias emergentes do effectuation (identidade, conhecimento e redes sociais). Dessa maneira, o estilo criativo na ação empreendedora guarda vinculação com a identidade no effectuation, do mesmo modo a expertise na ação empreendedora tem vinculação com o conhecimento no effectuation e, por fim, a interação social se relaciona com redes sociais.

\section{PROCEDIMENTOS METODOLÓGICOS}


O estudo assume o método qualitativo numa abordagem interpretativista de estudo de múltiplos casos em quatro estúdios de jogos indie. A escolha de estudar 4 estúdios, localizados em São Paulo (SP), Curitiba (PA), Recife (PE) e João Pessoal (PB), se justifica na medida em que reconhece a complexidade das experiências e dos processos dinâmicos vivenciados pelo produtor de jogos independente (BAUER; GASKELL, 2008; STAKE, 2009; GODOY, 2010). $\mathrm{Na}$ estratégia de coleta de dados foram realizadas entrevistas semi- estruturadas com os produtores de jogos eletrônicos indie, destacando que o desenvolvedor ouvido é o responsável pelo estúdio e todos os estúdios atuam no mercado indie de games. O tempo total de entrevista foi da ordem $5 \mathrm{~h} 19 \mathrm{~min} 11 \mathrm{~s}$, sendo um total de 1274 linhas, 36 páginas transcritas, portanto, a análise foi textual a partir das transcrições realizadas. A escolha da entrevista semi-estruturada se justifica pela possibilidade de o entrevistador conduzir a construção do corpus com liberdade, inserindo novas e relevantes questões no roteiro original (GIL, 2002).

A tabela 1 apresenta os dados dos estúdios participantes no que compete a localização, fundação e número de funcionários. As razões sociais (nomes)dos estúdios foram preservados, sendo substituídos por Alpha, Beta, Gama e Delta, como descrito na tabela 1.

Tabela 1: Empresas participantes do estudo

\begin{tabular}{clcc}
\hline STUDIO & \multicolumn{1}{c}{ ESTADO } & FUNDAÇÃO & COLABORADORES \\
\hline Alpha & João Pessoa - PB & 2014 & 10 \\
Beta & São Paulo- SP & 2013 & 5 \\
Gama & Curitiba-PA & 2012 & 2 \\
Delta & Recife-PE & 2005 & 40 \\
\hline \multicolumn{4}{c}{ Fonte: Elaborada pelo autor (2017) }
\end{tabular}

O Studio Alpha começou como um grupo de desenvolvedores de jogos, em abril de 2014, quando os três fundadores se uniram para criar o projeto de game LUX, o seu maior projeto, chegando a alcançar reconhecimento internacional. Já o Studio Beta é fabricante de jogos tem como destaque o lançado do jogo Head blaster, um jogo de árcade de PC gratuito e o Doti-Doti no Gaea, um jogo educacional móvel sobre reciclagem. O Studio Gama lança sua produção independente por intermédio de alguns parceiros, uma vez que não tem colaboradores e produz os jogos apenas em parceria. Por fim, o Studio Delta é um estúdio independente que não utiliza o trabalho do Publisher para as suas produções, mas, diferentemente da maioria dos estúdios Indie Games, sua liderança se preocupa com pré- produção, produção e pós-produção.

Os produtores independentes de jogos indie foram selecionados por estarem em regiões com destaque nacional na produção de jogos, ou seja, Sudeste, Sul e Nordeste do Brasil. Dessa maneira, foram selecionados (2) desenvolvedores no Nordeste do País, sendo um em Recife (PE) e o outro em João Pessoa (PB). Também foram selecionados outros dois desenvolvedores no Centro Sul do País, sendo um em São Paulo (SP) e outro em Curitiba (PR).

O processo de tratamento dos dados foi realizado conforme visto em Minayo (2010), sob a técnica de análise de conteúdo temática, nas entrevistas realizadas com os diretores da área tecnológica das empresas de game (Chief Tecnology Officers - CTO), considerando um 
dos elementos essenciais o emprego de categorias trazidas para o campo empírico com o suporte do software de análise de dados qualitativos NVivo, na versão 11 Pro (FLICK, 2013; SILVA, 2014). As categorias trazidas a priori para a análise são aquelas já definidas no item

2.3 do referencial, mais precisamente na figura 1 aqui reproduzida.

Figura 1: Ação Empreendedora e Effectuation

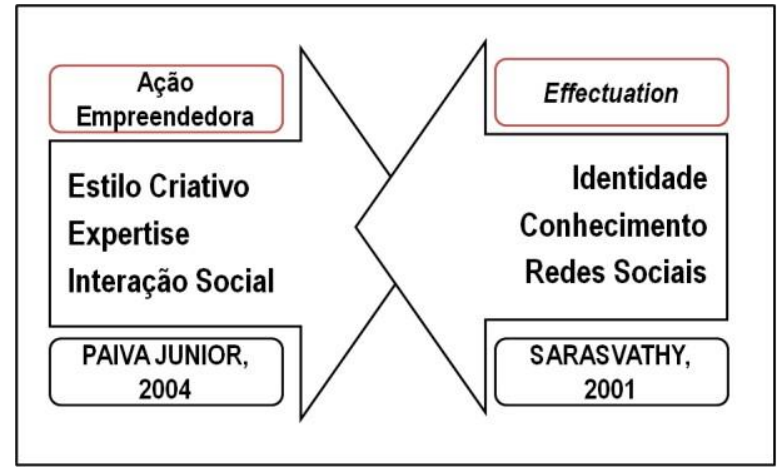

Fonte: Elaborado pelo Autor (2017)

\subsection{Tratamentos, análise e interpretação dos dados}

Foram realizadas as inferências e interpretações do corpus com respeito às dimensões estilo criativo, expertise e interação social, analisadas com o suporte da teoria do effectuation, proposta por Sarasvathy (2001), contemplando as categorias identidade, conhecimento e redes sociais. Para garantir a qualidade e confiabilidade dos dados, foi adotada a saturação interna e externa dos dados e dois tipos de triangulação: A validação convergente dos dados (FLICK, 2013) e a intersubjetiva (PAIVA JUNIOR; LEÃO; MELLO, 2011) com demais pesquisadores do grupo de pesquisa Lócus de Investigação em Economia Criativa (LIEC), da Universidade Federal de Pernambuco (UFPE).

\section{RESULTADOS E DISCUSSÃO}

$\mathrm{Na}$ análise de dados com a utilização do Nvivo Versão Pro, os significados mais atribuídos para a ação empreendedora dos produtores de games independentes foram: independente, desenvolvedor, empreendedor, desenvolvimento, effectuation, publisher, empreendedorismo, experiência, conhecimento, oportunidade, plataforma, indústria entre outros. Esses significados foram alcançados mediante processo de leitura e codificação de dados (figura 2) no Corpus deste estudo, como entrevistas. 
Figura 2: Termos mais usados para Ação empreendedora de produção de jogos Indie

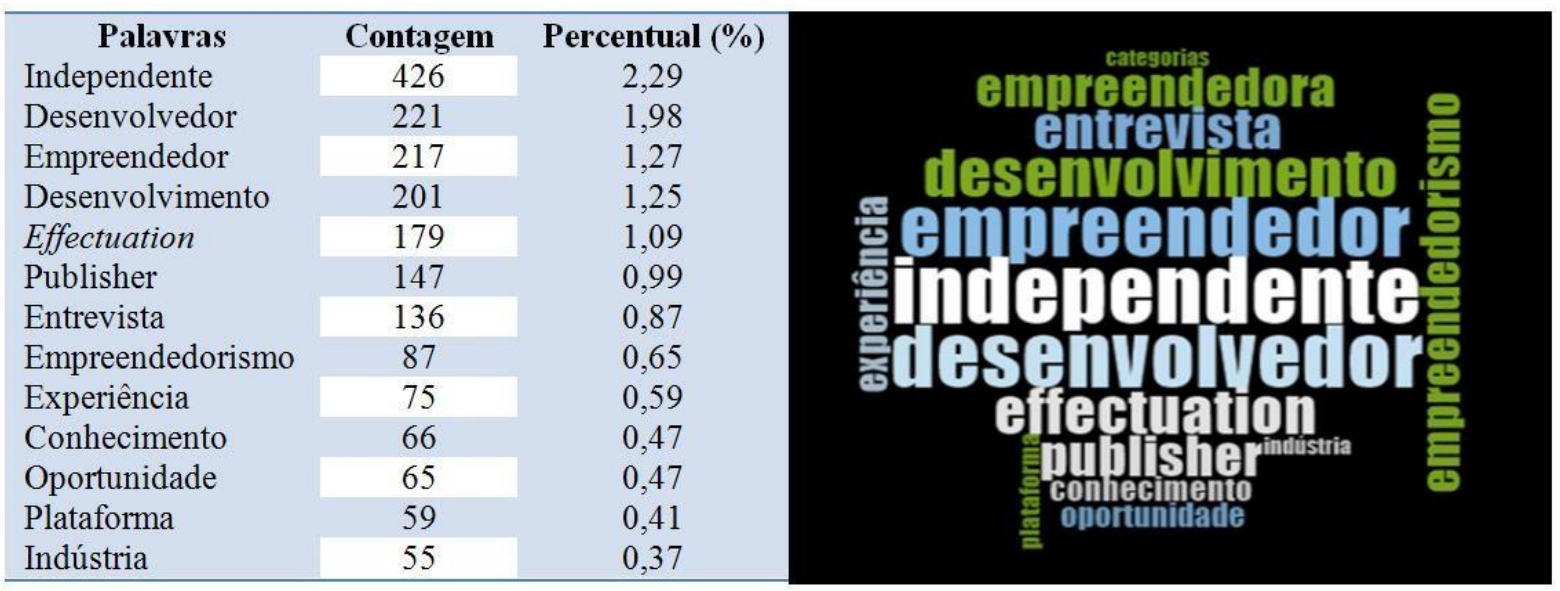

Fonte: Elaborado pelo autor (2017)

Mediante análise das categorias no Nvivo, foi possível identificar a suíte de categorias da ação empreendedora na produção de jogos independentes (indie) são representadas por hierarquia de frequencia dos vocábulos relativos à temática. Na categoria interação social, a dimensão com maior representatividade é a oportunidade, seguida por parceria; na categoria estilo criativo, a dimensão que mais se destaca é disposição pessoal e convivência com o risco; e na categoria expertise, a dimensão com maior representatividade é desenvolvimento de competências e mediação.

\subsection{Estilo criativo}

O estilo criativo é demarcado pela condição de um indivíduo ou de um grupo compreender os mecanismos distintos de operação, ou seja, o de construir elementos criativos e diferentes dos já construídos. Dessa categoria, emergem outras, como identidade, autonomia, convivência com o risco, disposição pessoal e resiliência. No estilo criativo o empreendedor se revela como agente capaz de intervir reflexivamente em dado cenário, uma vez que é dotado de uma bagagem de experiências que o posicionam de forma dialógica em sua produção.

Como dimensão dessa categoria, tem-se a convivência com o risco que ocorre pela ação ou efeito de se conviver com a possibilidade de risco ou perigo. Trata-se de um ambiente de tensões onde o desenvolvedor não tem o conhecimento do risco e de possíveis resultados da sua produção, elementos que estão associados à distribuição e comunicação mercadológica do seu produto o game.

O relacionamento com o Publisher é complicado, no geral ele busca extrair o máximo dos títulos que ele promove, ele tem recursos limitados para investir em novos títulos e ao mesmo tempo quer diminuir seu risco, então a abordagem é trazer muitos títulos e diminuir os riscos. Ele traz 50 títulos e investe em todos, no que ele
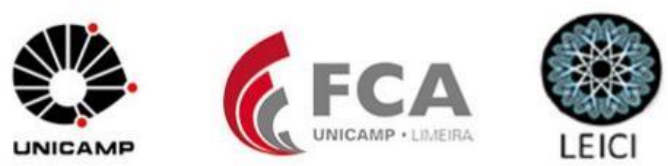
tiver mais retorno ele investe mais, assim se o game não apresentar retorno satisfatório em 30, 60, 120 dias é abandonado pelo Publisher (E1, Linha 104).

O publisher exerce uma ação propensa a riscos constantes num ambiente de incerteza, uma vez que uma produção de anos poderá ser descartada se não conseguir alcançar resultados significativos em poucos meses. Ao tratar da convivência com o risco nos princípios da lógica effectual Sarasvathy (2003) busca encarar os competidores como parceiros, diminuindo a incerteza das ações empreendedoras para os envolvidos. Por essa razão, para mitigar os riscos, os estúdios mantêm atividades de outsourcing, ofertando serviços especializados para indústrias correlatas (publicidade, como exemplo). Essa evidência vai se somando aos resultados de Perucia, Balestrin e Verschoore (2011), Negrão e Toaldo (2013) e Xavier Filho (2017) que encontram três estratégias para mitigação dos riscos no desenvolvimento de jogos: (i) A especialização funcional e a oferta de mão-de-obra para a indústria, seja ela a própria (games) ou via outsourcing para indústrias correlatas (cinema, publicidade, educação), (ii) $\mathrm{O}$ desenvolvimento de um portfólio de pequenos games publicados e (iii) Dedicação parcial da equipe no desenvolvimento do game, reduzindo os gastos fixos do estúdio.

Já a dimensão disposição pessoal compreende a capacidade de enfrentamento do empreendedor na aquisição de conhecimento e experiências por meio da prática. Essa categoria é marcada pela disposição do produtor de jogos indie em realizar diversas funções na construção do jogo, além de outra na vida diária, não relacionada ao game.

\begin{abstract}
Todos da equipe trabalham fora para pagar suas contas, porque a maioria dos nossos jogos é distribuída gratuitamente, salvo aqueles por encomenda. Eu trabalho com gamificação, produzindo jogos de tabuleiro e jogos digitais para recrutamento e seleção, nossa artista trabalha na construção de fachadas para lojas, nosso programador trabalha em uma empresa de MMO, são produtos plásticos superresistentes, nosso design é auditor numa empresa de comércio eletrônico e nossa comercial é jornalista (E2, Linha 9).
\end{abstract}

Não obstante a disposição pessoal dos desenvolvedores, os produtores de jogos indie buscam se realizar no jogo em termos de produtores e usuários lúdicos desses artefatos de diversão (RAMOS, 2008). Com isso, a teoria Effectuation sugere que o tomador de decisão não se associe à previsibilidade do cenário, mas atue como agente transformador que provê as condições necessárias para que o ambiente desse agente lhe seja benigno (WILBANK, 2006; PORTO, 2015).

\title{
4.2 Expertise
}

O termo expertise significa a existência de um conhecimento obtido pelo estudo, pela experiência acumulada, além de poder estar associado à habilidade de aplicar o que foi aprendido de uma área ou tópico devido ao seu estudo, treinamento ou experiência no assunto de maneira satisfatória (REIS, 2017). Na construção desse conhecimento, o empreendedor se mostra capaz de criar conhecimento, desenvolver e compartilhar os saberes de maneira satisfatória. 
Neste estudo, a expertise é uma categoria estrutural que está balizada pelas dimensões desenvolvimento de competências, alteridade, mediação, inovação. A dimensão desenvolvimento de competências está arraigada na capacidade de solucionar problemas que ainda não têm protocolos de solução, competências que instrumentalizam os empreendedores para enfrentamento das mudanças e das incertezas presentes no contexto da produção.

Trabalhamos com 100\% de produções próprias, já fizemos uma parceria com um pessoal da Colômbia e do Canadá, o bom desse relacionamento é que aprendemos e ensinamos ao mesmo tempo. Além de compartilhamos ferramentas e troca conhecimento, os desenvolvedores dos outros países estão mais atentos ao que funciona bem, sempre é um momento de aprendizagem (E4, Linha 64).

O desenvolvimento de competências na produção independente é construído por meio da prática empresarial. Nos extratos acima, a percepção de criatividade está vinculada à prática e à capacidade de conhecer, além do compartilhamento de ferramentas e troca de conhecimento. Essa ação se coaduna com o estudo de Múzzio (2017) quando declara que existem competências relacionadas à criação de determinada plataforma de conhecimentos voltada para o desenvolvimento de novas ideias, construção de uma visão compartilhada, emergência de clima organizacional favorável e encorajamento com o contexto externo, além do fomento da aprendizagem pela experiência.

\begin{abstract}
A maioria das soluções de gestão não se adapta bem ao nosso modelo de negócios, precisamos melhorar nossa divisão e entender melhor as receitas que vem de produtos e de serviço. Parece um problema simples de $4^{\circ}$ período de graduação, mas na prática não é, pois na produção de games esses elementos estão muito juntos até poderia dizer sobrepostos. Precisamos de um modelo de gerenciamento que seja sensível a essa questão (E1, Linha 60).
\end{abstract}

O relato acima apresenta a necessidade de desenvolvimento de novos modelos de gestão constituídos para a potencialização de negócios da economia do conhecimento. Para alicerçar um novo modelo de gestão direcionado a empresas de base tecnológicas (EBTs) Tasic (2007) e Andreassi (2015) sugerem que o effectuation, aplicado a contextos imprevisíveis, reconhecendo que nestas indústrias a lógica é dinâmica e com processos interativos de criação de oportunidade em novos domínios.

A dimensão mediação está centrada na busca por soluções que atendam ambas as partes em uma negociação, o desenvolvedor indie e o Publisher, evitando a sobreposição dos envolvidos e reduzindo o conflito entre expressão artística e produto comercial (PRYSTUPARZADCA;STAROSTKA (2015). Ela tem o papel de intervir entre as partes conflitantes com base no que é correto e justo, respeitando a igualdade no combate e a assimetria nas relações.

Uma questão que não pode se deixar de negociar é a interferência do Publisher na produção, se ele vai poder dizer como será o cenário, quantos níveis, quantos personagem, sobre o que o jogo vai tratar, se isso não estiver bem claro a produção poderá ter problemas (E3, Linha 147).

O fragmento aponta para um campo de tensão da produção independente, o da mediação realizada pelo mercado marca uma posição política para o Publisher e o Indie.

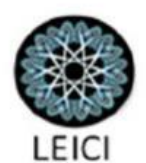


Diante da relação do mercado na condução do trabalho criativo, Caves (2003) afirma que a criatividade é negociada e quanto maior for o aporte financeiro do Publisher menor será o poder de decisão do produtor, tal situação que exige uma mediação para se evitar a assimetria no negócio.

\subsection{Interação social}

A interação social está marcada pelas relações que o desenvolvedor constrói em sua vida social e se fundamenta na afirmação de relações mútuas. Essa interação frente a uma ação empreendedora busca compreender não apenas as ações em seu significado aparente, mas também interpretar as motivações que o sujeito que empreende imputa (PAIVA JUNIOR, 2004; ELLISON; VITARK, 2015). A perspectiva analítica da ação empreendedora da produção de games independentes se dá sobre a marcação da interação social, com as dimensões oportunidade, parceria e valores, ação política e social, ação de adaptação contingencial, cooperação técnica e internacionalização.

A dimensão oportunidade está representada pela qualidade de existência daquele cenário favorável ao projeto daquele empreendedor. Ela é vista como dimensão capaz de auxiliar a melhoria de algo e promover um momento propício para a realização de algo novo, sendo entendida como a autopercepção, a vontade do desenvolvedor e a intenção de um parceiro em fazer emergir a oportunidade de novas produções.

Olhando para o mercado brasileiro, temos analisado que existe pouco conteúdo em português principalmente para o público infantil no campo da educação, analisei alguns simulados do ENEM e outras plataformas. Nesses simuladores a experiência dos usuários é terrível, você ficar 4 horas na frente de um celular respondendo, é desconfortável, gasta toda sua bateria. É melhor fazer a impressão da prova e responder. Então a gente identificou mais essa lacuna e estamos montando o nosso próprio conceito (E1, Linha 126).

No extrato acima (E1, Linha 126), a oportunidade real presente na produção de game está voltada para o mercado, mas existe dificuldade de interação social com protagonistas das plataformas existentes. Já a parceria e os valores estão demarcados pelos processos intersubjetivos de interação social que se efetivam por meio da realização de projetos motivada por valores coletivos.

Um diferencial do nosso Studio é nossa abertura para cooperação com outros estúdios além de trabalho com co-produção. Nesse relacionamento com outros desenvolvedores, trocamos experiências e aperfeiçoamos nosso trabalho. Não existe uma relação de esconder do outro tudo é feito. Recentemente fizemos uma parceria para digitalização do game, negociamos as porcentagens e os parceiros também são donos do jogo (E3, Linha 60).

Assim, o relacionamento entre os desenvolvedores com um ambiente de criação de parceira e valores vai além de troca de experiências e compartilhamento de ferramentas. 


\section{CONSIDERAÇÕES FINAIS}

O estudo se centra na compreensão da ação empreendedora dos produtores de jogos independentes. Para tal, as vantagens competitivas compatíveis com os recursos disponíveis e a mobilização do compromisso das partes envolvidas se efetivam para se alcançar objetivos compartilháveis. O effectuation é um modelo de tomada de decisão a partir de escolhas em meio aos efeitos que podem ser produzidos a partir de um dado conjunto de possibilidades, eliminando a premissa de objetivos pré-existentes, em que o empreendedor gera resultados a partir de combinações de recursos, à medida que reduz as incertezas.

Um dos elementos do estilo criativo que produz o empreendedor indie é a identidade que permite a diferenciação desse empreendedor. No relacionamento entre o publisher e o desenvolvedor existe um esforço por parte do primeiro no sentido de dar forma comercial ao game, fato que dificulta a autonomia e a criatividade do desenvolvedor, o Publisher quando investe em uma produção assume o papel de intermediário entre o produtor e o jogador e promove o jogo, levando a leitura do mercado para a produção do game. A disposição pessoal e a convivência com o risco estão presentes no desenvolvedor indie por sua atuação sem aporte financeiro de um Publisher, agente de fomento, sendo ele quem assume os riscos mercadológicos pelo artefato produzido. $\mathrm{O}$ sistema bancário tradicional não fornece crédito para esses desenvolvedores devido à incerteza da operação, ainda não estando alinhado a esse novo eixo da economia criativa, ainda enxergando com insegurança a produção no campo de design, música, fotográfica, games e demais eixos da economia criativa.

Sem alternativas de financiamento e aporte financeiro, esses desenvolvedores optam por modalidade de financiamento coletivo, a exemplo do crowdfunding, que vem se popularizando no Brasil nos últimos cinco anos. A disposição pessoal também se pauta pelo arranjo do produtor indie de atuar de maneira multifacetada, em muitos casos ter um emprego fixo, que traz segurança para pagar as contas, e, em segundo momento, atuar na produção do game, ação que revela resiliência por parte do desenvolvedor em meio a sua necessidade de produção e expressão criativa.

A produção indie se materializa como artefato digital por meio dos aplicativos para smartphones e mídias digitais, que são os principais meios de distribuição e comercialização do jogo. As plataformas permitem a hospedagem dos jogos e a inovação nesses dispositivos, possibilitando capilaridade, liberdade e autonomia para o desenvolvedor. A infraestrutura digital como sistema de computação em nuvens e a comunicação colaborativa levam à democratização da ação empreendedora na produção do jogo indie, aumentado o engajamento de um número maior de pessoas em todas as etapas do processo de construção do game.

$\mathrm{O}$ fenômeno indie está pautado por restrição de recursos, canais, meios e alianças, infraestrutura relacionada a um lançamento exitoso de produtos intensivos em tecnologia. A fim de mitigar seus riscos, os desenvolvedores constroem ferramentas de gestão que contemplam cronogramas, fluxogramas, planejamentos e ações a serem operacionalizados para a confecção e distribuição eficaz do jogo.

Existem aqui inquietações que merecem futuras pesquisas, a exemplo do modo como os desenvolvedores indie decidem o momento de desligar atividades com remuneração derivadas de riscos mais baixos para se dedicar exclusivamente a produção de games e como mantém uma atividade catártica (como a produção de games) quando estão imersos em

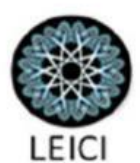


projetos em que o publisher interfere decisivamente no que deve ou não estar presente no game. Portanto, tais preocupações alcançam o fazer do empreendedor do jogo na modalidade de dedicação exclusiva com repercussão na sua busca por realização pessoal e profissional.

\section{REFERÊNCIAS}

BAUER, M.; GASKELL, G.; Pesquisa qualitativa com texto, imagem e som. 7 ed. Petrópolis: Vozes, 2008.

BERENDS, H., Jelinek, M., Reymen, I. M. M. J., Stultiens, R. G. L. Product innovation processes in small firms: combining entrepreneurial effectuation and managerial causation. Journal of Product Innovation Management, v. 31, p. 616-635, 2014.

BOCK, A. J. et al. The effects of culture and structure on strategic flexibility during business model innovation. Journal of Management Studies, v. 49, n. 2, p. 279-305, 2012.

CAVES, R. E. Contracts between art and commerce. The Journal of Economic

Perspectives, v. 17, n. 2, p. 73-83, 2003.

CHEN, C. Is the vídeo game a cultura vehicle? Games and Culture, v. 8, n. 6, p. 408-427, 2013.

DENTONI, D. et al. Aprendendo "quem somos" fazendo: processos de co-construção de identidades pro-sociais em empresas baseadas na comunidade. Journal of Business

Venturing, 2017.

ELLISON, N. B.; VITAK, J. Serviços de redes sociais e sua relação com os processos de capital social. O manual da psicologia da tecnologia da comunicação, v. 32, p. 205-228, 2015.

FLICK, U. Introdução à metodologia da pesquisa: Um guia para iniciantes. Porto Alegre: Penso 2013.

GEDIGAMES (Grupo de estudos e desenvolvimento da indústria de games). Mapeamento da indústria brasileira e global de jogos digitais. Contrato BNDES-FUSP: São Paulo, Fevereiro de 2014.

GIL, A. C. Como elaborar projetos de pesquisa. São Paulo: Atlas, 2002.

GODOY, A.S. Estudo de caso qualitativo. In: GODOY, C. K.; BANDEIRA DE MELO, R.; SILVA, A.B. (Org). Pesquisa qualitativa em estudos organizacionais: Paradigmas, estratégias e métodos. 2 ed. São Paulo: Saraiva, 2010.

JOHNS, J. Video games production networks: value capture, power relations

andembeddedness. Journal of Economic Geography, v. 6, n. 2, p. 151-180, 2006

LEUCZ, T.; ANDREASSI, T. O processo decisório e o uso das lógicas effectuation e causation, frente à transição da pequena para a média empresa: casos do setor hoteleiro na cidade de Curitiba-PR. Revista Brasileira de Pesquisa em Turismo, v. 9, n. 3, p. 400-421, 2015.

MEYER, J.W.; ROWAN, B. Institutionalized Organizations: Formal Structure as Myth and Ceremony. AmericanJournal of Sociology, v. 83, n. 2, p. 340-363, 1977.

MINAYO, M.C.S. O desafio do conhecimento: pesquisa qualitativa em Saúde. 12 ed. São Paulo: Hucitec, 2010. 
MUZZIO, H. Indivíduo, liderança e cultura: evidências de uma gestão da criatividade/individual. Leadership and culture: evidence of creativity management. Revista de Administração Contemporânea, v. 21, n. 1, p. 107, 2017.

NAMBISAN, S. Digital entrepreneurship: Toward a digital technology perspective of entrepreneurship. Entrepreneurship Theory and Practice, v. 41, n. 6, p. 1029-1055, 2017. NEGRÃO, M. D. A.; TOALDO, A. M. M. Processo de implementação de estratégias de marketing na indústria criativa de jogos eletrônicos. Revista Ibero-Americana de Estratégia, v. 12, n. 2, p. 105-137, Abr./Jun., 2013.

PAIVA JUNIOR., F. G. O empreendedorismo na ação de empreender: uma análise sob o enfoque da fenomenologia sociológica de Alfred Schütz. 2004. Tese (Doutorado).

Universidade Federal de Minas Gerais, Belo Horizonte, 2004.

PAIVA JÚNIOR, F. G.; LEÃO, A. L. M. S.; MELLO, S. C. B. Validade e Confiabilidade na Pesquisa Qualitativa em Administração. Revista de Ciências da Administração, v. 13, n. 31, p. 190-209, set./dez., 2011.

PEREIRA, J. A.; BERNARDO, A. Empreendedorismo digital: Estudo do projeto negócios digitais realizados pelo SEBRAE-PR em Maringá. Desenvolvimento em Questão, v. 14, n. 37, 2016.

PÉREZ, O. L. The social discourse of video games analysis model and case study: GTA IV. Games and Culture, v. 10, n. 5, p. 415-437, 2015.

PERUCIA, A.; BALESTRIN, A.; VERSCHOORE, J. Coordenação das atividades produtivas na indústria brasileira de jogos eletrônicos: Hierarquia, mercado ou aliança? Produção, v. 21, n. 1, p. 64-75, Jan./Mar., 2011.

PORTO, P.; DE MELLO, R. C. Empreendedorismo internacional e effectuation: O caso do Café Yaguara Ecológico. Internext, v. 10, n. 3, p. 15-30, 2015.

PRYSTUPA-RZADCA, K.; STAROSTKA, J. Customer involvement in the game development process. Journal of Entrepreneurship Management and Innovation, v. 11, n. 3, p. 43-66, 2015.

RAMOS, D. K. A Escola frente ao fenômeno dos Jogos Eletrônicos: Aspectos Morais e Eticos. Revista Novas Tecnologias na Educação, v. 6, n. 2, p. 1-10, jul., 2008.

REIS, F. L. et al. Criatividade e inovação: o uso dos games na educação. Revista Expressão, v. 1, n. 1, p. 16, 2017

REYMEN, I. et al. Decision making for business model development: a process study of effectuation and causation in new technology-based ventures. R\&D Management, 2016. RIFKIN, J. The Age of Access: The New Culture of Hypercapitalism, Where All of Life Is a Paid-for Experience. Harmondsworth: Penguin, 2000.

RONDANI, B.; ANDREASSI, T.; BERNARDES, R. C. Microfoundations for Open Innovation: is Effectuation a valid approach for open innovation managers? Revista Gestão e Conexões, v. 2, n. 1, p. 94-115, 2013.

SALUSSE, M. A. Y.; ANDREASSI, T. O Ensino de Empreendedorismo com Fundamento na Teoria Effectuation. Revista de Administração Contemporânea, v. 20, n. 3, 2016.

SANSON, C. A produção biopolitica é constitutiva ao capitalismo cognitivo. Liinc em Revista, v. 5, n. 2, p. 206-214, Set., 2009. 
SARASVATHY, S. Causation and effectuation: Towards a theoretical shift from economic inevitability to entrepreneurial contingency. Academy of Management Review, v. 26, p. 243-288. 2001.

SARASVATHY, S. D.; DEW, N. New market creation through transformation. Journal of Evolutionary Economics, v. 15, n. 5, p. 533-565, 2005.

SARASVATHY, S. Entrepreneurship as a science of the artificial. Journal of Economic Psychology, v. 24, n. 2, p. 203-220, 2003.

SARASVATHY, S.; KOTHA, S. Effectuation in the management of knightian uncertainty: evidence from the realnetwork case. UW Business School Working Paper, 2001. Disponível online em: <http://www.effectuation.org/wp-content/uploads/2016/06/2001realnet-1.pdf>, em 6 Mar. 2018.

SHAW, A. What is video game culture? Cultural studies and game studies. Games and Culture, v. 5, n. 4, p. 403-424, 2010.

SILVA, A. D. F. O processo regulador na [Re]conversão de um arranjo produtivo local: O caso do Portomídia - Centro de Empreendedorismo e Tecnologia da Economia Criativa. 113f. Dissertação (Mestrado em Administração). Universidade Federal de Pernambuco. Centro de Ciências Sociais Aplicadas. Recife: UFPE, 2014.

SOUZA, J. L. de; PAIVA, JR., F. G. de. Empreendendo no setor público - A dinâmica da Fundação Joaquim Nabuco. Recife: Fundação Joaquim Nabuco, 2012.

SPEDALE, S.; WATSON, T. J. The emergence of entrepreneurial action: At the crossroads between institutional logics and individual life-orientation. International Small Business Journal, v. 32, n. 7, p. 759-776, 2014

STAKE, R. A arte da investigação com estudo de caso. 2.ed. Lisboa: Fundação Calouste Gulbenkian, 2009.

TASIC, I. A. B. Estratégia e empreendedorismo: decisão e criação sob incerteza. Tese (Doutorado em Administração). 142f. Fundação Getúlio Vargas. Escola de Administração de Empresas de São Paulo. São Paulo: FGV, 2007.

THEODORAKOPOULOS, N. et al. Diversifying into technical clothing manufacture as entrepreneurial learning: A situated learning theory perspective. Journal of manufacturing technology management, v. 25, n. 5, p. 676-693, 2014.

VON BRIEL, F.; DAVIDSSON, P.; RECKER, J. Digital technologies as external enablers of new venture creation in the IT hardware sector. Entrepreneurship Theory and Practice, v. 42, n. 1, p. 47-69, 2018.

WILLIS, S. Cotidiano: Para começo de conversa. Rio de Janeiro (RJ): Paz e Terra, 1997. WILTBANK, R.; DEW, N.; READ, S.; SARASVATHY, S. Whatto Do Next? The Case for Non-Predictive Strategy. Strategic Management Journal, v. 27, n. 10, p. 981-998, 2006. XAVIER FILHO, J. L. J. Jogos eletrônicos como mediação comunicativa da cultura: Um olhar a partir da Cultura da Produção. 186f. Tese (Doutorado em Administração). Universidade Federal de Pernambuco. Centro de Ciências Sociais Aplicadas. Recife: UFPE, 2017. 